\title{
A Aprendizagem da Dor
}

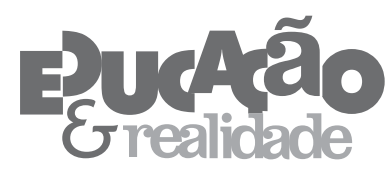

\section{Nadja Hermann'}

'Universidade Federal do Rio Grande do Sul (UFRGS), Porto Alegre/RS - Brasil

RESUMO - A Aprendizagem da Dor. O interesse pela pandemia extrapola a área de especialistas em saúde pelas repercussões em todos os âmbitos da vida, particularmente na educação. Ao mesmo tempo que traz o estranho, o que é ameaçador, desestabilizando a ordem vigente, a dolorosa experiência mobiliza nossa capacidade de sentir e aprender. Dessa aprendizagem da dor já é possível recolher as primeiras lições da pandemia: o reconhecimento da vulnerabilidade da condição humana, a importância da verdade para enfrentar os problemas e a solidariedade com o outro. O artigo conclui que a aprendizagem e o saber mais amplo decorrentes dessas lições tem uma força transformadora, que se constitui numa espécie de superação, não no sentido de um sentimentalismo ingênuo, mas algo que surge da própria situação dolorosa, pois, como percebe Hölderlin, justamente onde há o perigo cresce a salvação.

Palavras-chave: Aprendizagem. Vulnerabilidade. Verdade. Solidariedade.

ABSTRACT - Learning from Pain. The interest in the pandemic goes beyond the health professionals' area of expertise due to repercussions in all areas of life, particularly in education. At the same time that it brings the foreign, what is threatening, destabilizing the current order, the painful experience mobilizes our capacity to feel and learn. From this learning through pain, it is already possible to take the first lessons of the pandemic: the recognition of the vulnerability of the human condition, the importance of truth to face problems, and solidarity with others. The article concludes that the learning and broader knowledge resulting from these lessons have a transformative force, which constitutes a kind of overcoming, not in the sense of naive sentimentality, but something that arises from the painful situation itself, because, as Hölderlin realizes, precisely where there is danger, salvation thrives.

Keywords: Learning. Vulnerability. Truth. Solidarity.

Educação \& Realidade, Porto Alegre, v. 45, n. 4, e110033, 2020.

http://dx.doi.org/10.1590/2175-6236110033 
E não se podia encontrar ninguém que, numa tal ocasião, não tivesse sido experimentado pela doença, pela morte ou pelo luto (Lucrécio Caro, Da natureza).

Mas onde há perigo,

cresce também aquilo que salva (Hölderlin, Patmos)

\section{Primeiras Palavras}

Na história epidemiológica há registro de grandes pandemias, todas virulentas e ameaçadoras. Lembremos apenas duas das mais conhecidas: a peste bubônica que atingiu a Europa entre 1347-1351, matando 200 milhões de pessoas, e a gripe espanhola, que teve início em 1918, com uma estimativa entre 40 a 50 milhões de mortos ${ }^{1}$. Mesmo sabedores disso, atônitos e com medo, assistimos ao surgimento da Covid-19, algo inusitado, uma vez que não havíamos vivido uma experiência dessa magnitude, deixando inclusive governos desorientados. Convém destacar que epidemiologistas não chegam a se surpreender e especialistas em informática médica alertam sobre a probabilidade de "uma pandemia maior que a atual", tendo como "base a possibilidade teórica de mutações de vírus" (Massad, 2020). Mas se a abordagem epidemiológica e médica cabe aos especialistas, o interesse pela pandemia extrapola em muita a área especializada, assumindo grande amplitude, pois a doença e a morte repercutem em todas as dimensões da vida. Pelo impacto avassalador que provocam, as pestes instigam o pensamento, numa espécie de convocação à reflexão, à apreciação legítima da realidade, como se observa no famoso poema filosófico de Tito Lucrécio Caro (ca. 96 a. C. - ca. 55 a. C.), Da natureza (De Rerum Natura), cujos últimos versos narram a peste que abalou Atenas, na antiga Grécia, em 430 a. C., durante a Guerra do Peloponeso, deixando antever, em bela rítmica, uma intenção pedagógica. O poema retoma, com notável talento poético, a filosofia materialista de Epicuro ${ }^{2}$, segundo a qual a natureza é um grande sistema em que todas as partes se acham em relação recíproca. Tudo é composto por elementos em perpétuo movimento e a vida humana está submetida às mesmas condições que regem o universo, numa dinâmica entre movimento criador e destruidor presentes na natureza. Conhecendo o sistema da natureza, o homem pode afugentar os horrores e dispersar os obscurantismos da mente, afastar o medo dos deuses e da morte incutidos pelas religiões e, assim, buscar a felicidade. A catastrófica pandemia referida no poema ensina a humanidade que os males que a afligem não são causados por castigos divinos: "Já não tinham importância nenhuma nem a religião nem os numes dos deuses: a dor presente era muito mais forte" (Lucrécio, 1973, VI, 1279). Os males se dissipam pela correta compreensão da natureza das coisas, essa é a lição da filosofia de Epicuro que o poeta quer mostrar. Note-se que era comum em textos antigos a referência à peste, como se observa no início do Édipo Rei, de Sófocles, mas, nesse caso, está associada ao castigo divino. Em Da natureza, a introdução da peste não tem mais esse sentido; ao contrário, é uma aposta na ratio. 
Apesar da longa história das pandemias e seus impressionantes registros, com a Covid-19 vivemos uma situação singular, tanto por sua magnitude e consequências já visíveis como por aquelas ainda não dimensionadas. Sua capacidade de contágio foi altamente potencializada devido às condições da sociedade globalizada, com grandes aglomerações urbanas e populações de alta densidade geográfica e intensa mobilidade. A epidemia avançou rapidamente ${ }^{3}$ e após breves períodos de controle retorna em novas ondas, evidenciando que na natureza há sempre algo que escapa, como ensinavam os gregos antigos. Já a ciência moderna quer desvelá-la, apostando em novas condições epistêmicas e tecnológicas para dominá-la, como indica a chegada da vacina. Tentamos controlar tudo o que está a nossa volta, mas a natureza exerce muito mais poder do que supúnhamos. Diante dessa situação pandêmica, Habermas (2020), em entrevista ao Jornal Frankfurter Rundschau, afirma: "nunca se soube tanto sobre nosso não saber e sobre a pressão de atuar e viver na incerteza".

Acostumados que estávamos com respostas médicas quase imediatas para muitas doenças, a epidemia trouxe à luz a fragilidade humana e a imprevisibilidade dos riscos e das consequências sociais e econômicas, provocando desorientação e desamparo. Não tivemos a chance de nos refugiar em outra cidade para escapar da peste como fizeram as personagens de Decameron, de Boccaccio (2002), no século XIV, ao serem acometidas pela peste negra. Fuga que se traduziu numa forma de superação da morte e do desespero. Tal exemplo não é uma mera ilustração, tampouco uma ironia; na verdade, Decameron permite um exercício comparativo entre dois períodos históricos diversos, evidenciando que, apesar do alto grau de desenvolvimento tecnológico, ficamos sem refúgio, quase imobilizados pelo alto grau de transmissibilidade do patógeno. Tentando evitar o contágio, os governos adotaram medidas como distanciamento social e isolamento, proibição de viagens, fechamento do comércio e da indústria, ampliação da infraestrutura hospitalar, além da obrigatoriedade do uso de máscara e cuidados de higiene. Enquanto estes últimos cuidados dependem do grau de responsabilização de cada indivíduo, a ciência assume a responsabilidade social, concentrando esforços coletivos em pesquisas para conhecer o vírus e produzir vacinas. $\mathrm{O}$ fechamento das escolas foi uma das medidas mais perturbadoras, sobretudo porque privou a interação entre crianças, aspecto decisivo no seu próprio desenvolvimento e aprendizagem.

\section{Quais Lições Aprendemos com a Pandemia?}

Pode-se afirmar que há uma dimensão fenomenológica na pandemia como um acontecimento que traz o estranho, o que é ameaçador, porque desestabiliza a ordem vigente, cria interditos, desautoriza respostas habituais, impondo novos modos de organização da vida e de relacionamento com os outros, além da adoção de medidas extraordinárias, muitas delas só conhecidas em estados de guerra. Tais mudanças acarretam inquietação, perturbação e insegurança existencial. 
O quanto somos afetados depende do amplo espectro de fatores associados à pandemia - as características do patógeno, a disponibilização de redes de proteção à saúde, as condições sociais, psíquicas, econômicas e políticas - e do grau de esclarecimento científico e educativo. Este último será decisivo em nossa própria proteção e no controle da transmissão do vírus.

O significado dos impactos e das mudanças na vida cotidiana e social provocado pela Covid-19 ainda está sendo avaliado. A dolorosa experiência atinge profundamente não só o corpo, como também o espírito humano, tornando incontornáveis certas perguntas, mobilizando nossa capacidade de sentir e aprender, pois o pensamento crítico não se detém, se lança em busca de possibilidades interpretativas. Um olhar atento à dinâmica interna da aprendizagem desencadeada pela epidemia em suas múltiplas implicações - a despeito da persistência de incertezas - já permite recolher as primeiras lições extraídas da experiência. A presente Seção Temática foi produzida nessa perspectiva: $\mathrm{O}$ que aprendemos? Quais lições se impõem?

Intitulada esta Seção como As Lições da Pandemia, faz-se oportuno um breve esclarecimento sobre o emprego do termo. Lições aqui não se referem àquilo que se transmite por ensino, nem qualquer forma de transmissão do saber, mas se vinculam às origens persistentes da atividade de aprender profundamente enraizadas na experiência da vida. Das grandes catástrofes humanas podemos aprender algo verdadeiramente vital, pois transmutam nossa compreensão, trazem o tema em questão para um novo tópos. Trata-se de mudanças na consciência, da instauração de um saber da "experiência que se faz" (Gadamer, 1990, p. 359). O conceito de experiência em Gadamer é potente para dimensionar o sentido radical de aprender uma lição. Como não há propriamente uma teoria da experiência e tampouco deve ser confundida com a experimentação científica que depende de repetição, Gadamer retoma, a partir da dialética hegeliana, o caráter de negatividade da experiência, justamente por considerar que, nesse aspecto, há um notável acerto de Hegel. Ou seja, na experiência somos confrontados com a estrutura de negatividade, o que não significa negar os fatos, como ocorre nas mentes eivadas de negacionismo e fundamentalismo. Ao contrário,

[...] significa que até então não havíamos visto corretamente as coisas e que só agora nos damos conta de como realmente são. Assim, a negatividade da experiência possui um sentido marcadamente produtivo. Não é simplesmente um engano que é visto e corrigido, mas representa a aquisição de um saber mais amplo (Gadamer, 1990, p. 359).

Aquele que experimenta o sofrimento, o medo e as restrições impostas pela pandemia volta-se para si mesmo (inverteu-se em termos de dialética hegeliana) e ganha assim novo horizonte, dentro do qual algo se converte em experiência para ele mesmo. Por meio do saber mais amplo promovido pela experiência se alteram o próprio entendimento sobre a situação e sobre nós mesmos, pois se reconhece aquilo que aparecia como estranho. 
Faz parte da estrutura da experiência a frustração de muitas expectativas, sendo, de certo modo, uma aprendizagem da decepção, o que a torna dolorosa, mas não deve ser confundida com pessimismo. A experiência prepara o discernimento, que não é simplesmente saber algo específico a respeito de um estado de coisas, mas “[...] contém sempre um retorno de algo que estávamos presos por cegueira. Nesse sentido, [discernimento] implica sempre um momento de autoconhecimento" (Gadamer, 1990, p. 362). Portanto, o que aprendemos e compreendemos pela experiência tem um caráter formativo, prepara nossa capacidade de ponderar, habilitando juízos mais precisos e ampliando o horizonte interpretativo, o que mantém a abertura a novas experiências.

Os efeitos catastróficos de uma pandemia nos ensinam a buscar respostas operacionais, científicas e técnicas tais como investir na pesquisa científica, ampliar redes de atendimento hospitalar, buscar formas de conduzir o ensino por meios de tecnologias de informação etc. São respostas decisivas no enfrentamento técnico do problema, mas a pandemia ensina também a pensar o sofrimento. A aprendizagem da dor nos faz experienciar a finitude humana, que, na sua forma mais autêntica, conduz "[...] ao limite absoluto todo dogmatismo nascido da alma humana que se deixa dominar por seus desejos" (Gadamer, 1990, p. 363). A experiência da finitude permite dissipar as diferenças entre as expectativas realistas e os desejos.

Entre as lições aprendidas com a pandemia, destaca-se em primeiro lugar o reconhecimento da perturbadora vulnerabilidade humana. Situações trágicas e dolorosas constituem-se em um dos primeiros ensinamentos contra a autossuficiência humana, porque nos confronta com limites, lembra que somos mortais e que não há nenhum sentido em pretender características divinas. Aprendemos que não devemos apenas nos proteger contra o terrível contágio do vírus, mas que a vulnerabilidade nos torna também dependentes de informação qualificada, das redes de proteção à saúde, das políticas públicas e da educação institucional (escolas, Universidades). Reconhecer a vulnerabilidade e vencer o abismo da onipotência se impõem como condição de empatia e de solidariedade para nos compadecermos com o sofrimento do outro, que na pandemia assume grande proporção, tanto pela doença como pela morte.

A vulnerabilidade expõe, sobretudo, a nossa dependência da interação humana, sobretudo seu caráter fundante para o processo educativo, uma vez que mesmo as experiências mais exitosas de educação remota não contemplam aquilo que o encontro humano oferece. A exclusividade do ensino remoto foi circunstancial, mas evidenciou, contra um contentamento ingênuo e, às vezes eufórico, que a formação exige, além do confronto do sujeito consigo mesmo, o encontro com os outros na perspectiva de amadurecimento da própria identidade, capacidade de deliberação e abertura ao outro. Mead (2008) demonstrou de forma inequívoca o quanto interação e educação se relacionam. 
De uma segunda lição aprendemos que, para enfrentar os problemas, não necessitamos de ilusões e sim de verdade. Essa certamente é uma dura lição, pois tem no seu cerne a pergunta de Nietzsche: "Quanta verdade suporta, quanta verdade ousa um espírito?” (Nietzsche, 1988, p. 258). A grandiosidade dessa pergunta vai contra a estreiteza das mentes que insistem em questionar o estatuto da ciência, operando num plano meramente ideológico, inspirado em teorias da conspiração. A epistemologia reconhece que a realidade assume diferentes perspectivas, que há pontos de vista divergentes, mas seria falacioso não reconhecer que a ciência nos dá um conhecimento confiável da realidade, que, sob determinadas condições epistêmicas e técnicas, podemos chegar à verdade, que se sabe provisória, mas não se afunda num relativismo insustentável. Por isso, nem todas as maneiras de lidar com um problema são corretas, pois há consensos científicos que podem indicar os melhores caminhos. Como observa Alfredo Marcos, no artigo que integra esta Seção Temática: "A frivolidade relativista se evaporou diante da constância cruel da realidade que nos golpeia” (2020, e109147).

Nossa compreensão e nosso conhecimento dependem do enfrentamento da realidade e dos fatos, de provas racionais e não da torrente de informações (muitas falsas, fake news) e confabulações que apenas ofuscam o discernimento e reafirmam as próprias crenças de quem as divulga. No século I a. C., o empenho de Lucrécio, no poema referido anteriormente, foi sobrepujar o obscurantismo associado à religião e ao medo dos deuses, a ser superado pelo conhecimento da natureza. Hoje o obscurantismo que assombra está associado ao fundamentalismo anticientífico que nega a verdade, a gravidade da epidemia e ainda despreza as orientações de como proceder, desafiando, inclusive, importantes instituições como os Institutos de pesquisa e as Universidades, que sustentam os processos de conhecimento, baseados em verdades justificadas e comprovadas, que promovem benefícios à humanidade. Igualmente desacreditam a escola enquanto um espaço privilegiado de formação científica, de preparo para uma mentalidade aberta e crítica. Quanto mais limitada for a compreensão de alguém mais forte será a tendência em negar a verdade e tudo aquilo que não se ajusta aos seus esquemas assimiladores e às ideologias, num egocentrismo obtuso.

Esse negacionismo produz uma espécie de brutalidade que, além de desfigurar o estatuto da ciência, traz consequências desastrosas no plano político e social, como observam, em artigo desta Seção Temática, Duarte e César (2020, e109146):

[...] o negacionismo é um fenômeno político porque, o mais das vezes, está associado com a extração de vantagens políticas por parte de grupos econômicos interessados em negar ou questionar teses e conhecimentos científicos. Isto ocorre, sobretudo, quando tais conhecimentos inspiram políticas públicas destinadas a transformar comportamentos e modos de vida coletivos, os quais afetam interesses econômicos poderosos. 
Em terceiro lugar, aprendemos a lição de que não se avança na superação da epidemia, sem solidariedade e coesão de esforços. Somos seres vulneráveis e dependentes, encontramo-nos entrelaçados numa rede de interdependência social, que exige cuidados recíprocos. O que parece ser um simples regramento sanitário - fique em casa, evite aglomerações - encerra também um juízo ético. Esse tipo de juízo considera as razões internas e específicas de cada caso que é objeto de decisão, a cultura, os valores, a relação com o outro e tudo aquilo que julgamos ser digno de afeição, que atua sobre nossos desejos, nosso caráter e vinculações pessoais. Assim, a decisão de seguir uma norma sanitária diante de uma poderosa pandemia ultrapassa o nosso eu e nos coloca diante da alteridade, do que posso fazer para ser solidário, de como posso colaborar para não pôr a vida dos outros em risco. A pandemia exige, por detrás do regramento sanitário, uma resposta ética, que é a solidariedade $^{4}$.

Habermas chama a atenção ao fato de nossas intuições morais nos informar a respeito da melhor forma de nos comportarmos diante da situação de extrema vulnerabilidade dos indivíduos. Nessa perspectiva, a ética atua como um "dispositivo de proteção" que compensa a vulnerabilidade da vida (Habermas, 1991, p. 14). A solidariedade é entendida como a força de um sentimento que vincula os membros de uma sociedade, ou seja, cria um sentimento de pertença, reivindica "empatia e cuidado em relação ao bem-estar do próximo” (Habermas, 1991, p. 16). O ego, como diz Habermas, "tem que ser capaz de imaginar como é que cada um se transfere para a situação do outro” (Habermas, 1991, p. 59).

A capacidade de permutar perspectivas leva o sujeito a se tornar solidário com o outro, independentemente de laços pessoais e identitários, como ocorreu durante a pandemia, quando muitas atitudes benevolentes e práticas concretas de auxílio e de cuidado (distribuição de alimentos para populações carentes, auxílio de busca hospitalar, realização de compras de mantimentos para pessoas isoladas etc.) auxiliaram o bem-estar de pessoas fragilizadas. Igualmente a solidariedade se impõe como empatia e compromisso humano em relação à dor e ao luto daqueles que perderam familiares e amigos. Por outro lado, a epidemia também expõe a falta de responsabilidade solidária no mau exemplo de autoridades públicas e de pessoas que permanecem indiferentes ao sofrimento alheio e desrespeitam as recomendações de prevenção, como usar máscaras e evitar aglomerações.

A possibilidade de imaginar-se na situação do outro requer uma tonalidade afetiva, uma disposição afetiva, que ultrapasse o egoísmo e as lealdades restritas aos grupos de pertencimento. Isso é uma tarefa a ser preparada cuidadosamente por uma educação atenta à sensibilidade, que estimule experiências solidárias, de modo a desbloquear rígidas crenças e nos tornar mais capazes de interpretar as situações de vulnerabilidade em relação aos outros.

A três lições referidas - vulnerabilidade da condição humana, a busca da verdade para enfrentar os problemas contra as brumas da ignorância e a solidariedade com o outro - são lições aprendidas de um 
tempo de dor. Elas não são totalmente estranhas para nós, mas são redimensionadas pelo caráter avassalador da pandemia, e o saber mais amplo que daí resulta tem uma força transformadora, constitui-se numa espécie de superação, não no sentido de um sentimentalismo ingênuo, mas como uma força que brota ali mesmo onde se encontra a situação, como canta a lírica de Hölderlin nos versos que integram a epígrafe deste texto, pois, justamente onde há o perigo, a dor, aí nasce a salvação.

\section{Detalhando as Lições: os artigos que integram a seção temática}

Os artigos que integram a Seção Temática destacam as nuances das lições aprendidas nessa dolorosa pandemia. Traduzem em argumentos e refinamento conceitual as muitas inquietações que nos afligem, no empenho em evidenciar e compreender suas repercussões na educação escolar, na vida social e política. Há aqui uma pluralidade de enfoques, em que cada articulista interpreta a experiência da pandemia na perspectiva de suas investigações.

Christoph Türcke, pesquisador alemão da área da filosofia, empresta à Seção Temática um olhar apurado em Medo e razão em tempos de coronavírus, interpretando a profundidade do choque causado pelo vírus e o medo que provoca como um insulto narcísico, pois o vírus provém de uma força da natureza, que se supunha superada na era da alta tecnologia. O medo nada tem de irracional desde que não se sucumba a mitos conspiratórios e raciocínios distorcidos. A pandemia só amplifica tendências já existentes, como, por exemplo, o caso emblemático da indústria das tecnologias da informação, que se autoapresenta como solução e "furtivamente, fará desaparecer toda uma dimensão da realidade, que todos afirmam ser insubstituível”. Türcke conclui que essa situação só mudará se houver resistência.

Alfredo Marcos, pesquisador espanhol de tradição aristotélica, no artigo Con covid y sin covid: la vulnerabilidad humana, alerta que a lição aprendida da Covid - a vulnerabilidade - não é nova, mas é algo que esquecemos. Ela se mostra na impossibilidade de nos protegermos perfeitamente, pois nem a ciência nem a tecnologia podem tudo predizer e controlar. Tampouco temos um guia seguro para orientar nossas ações. Tais orientações surgem da realização de nosso ser pessoal, seguindo o naturalismo moderado de Aristóteles. Como somos animais racionais, temos uma base biológica que nos faz vulneráveis. Mas enquanto racionais podemos argumentar, pensar, nos orientar pelo bem e promover as virtudes que conduzem à realização pessoal, de modo a contemplar a mútua dependência entre a condição animal, social e espiritual. É dessa condição, conclui Marcos, "que brota nossa força formativa".

Em Nihilismo, pandemia y educación, Andrea Díaz, pesquisadora uruguaia na área de filosofia da educação, analisa, de forma ensaística, as consequências da pandemia numa perspectiva existencial. Diante da noite escura que a pandemia representa se estabelece um nihilismo, uma descrença em qualquer progresso racional e uma desesperança. 
Todavia, a ideia de nihilismo ativo em Nietzsche aciona uma forma de saída, uma possibilidade de sentido a partir da imanência, que pode ser obtida pela experiência de resistência íntima, sugerida por Esqueirol, que reivindica tanto o cuidado de si e do outro como também uma resistência política. Se estamos presos a espaços virtuais, pode-se usar esses mesmos meios para resistir ao poder e seus perigos. A escola na pandemia promove um encontro com o aluno, que, mesmo sendo virtual "é um encontro que sustenta a relação com o mundo por meio de um saber de uma disciplina”. A educação é, assim, um lócus dessa resistência, um lugar de "renovação do mundo e de esperança".

André Duarte, pesquisador na área de filosofia política, e Maria Rita de Assis César, pesquisadora na área educação, analisam os impactos do negacionismo tanto na gestão da pandemia como na democracia brasileira, no artigo Negação da política e negacionismo como política: pandemia e democracia. Discutem o problema da negação em dois registros: primeiramente analisam a estratégia da negação da política usada por Jair Bolsonaro, que, sem romper definitivamente com a democracia, passou a afrontá-la. Num segundo momento, discutem a estratégia do negacionismo como política no modo de conduzir a gestão da pandemia. Por fim, apontam como essas duas estratégias "[...] se conjugaram, produzindo fenômenos sócio-políticos que corroem a democracia, como a banalização das mortes e a naturalização da clivagem entre vidas valiosas, vidas submetidas a processos de menos-valia e vidas descartáveis".

Alfredo Veiga-Neto, pesquisador na área da educação, em Mais uma lição: sindemia covídica e educação, inicialmente, justifica o emprego do termo sindemia, por se tratar de "conceito poderoso para uma compreensão mais abrangente e refinada dos problemas criados pelo novo vírus". Na sequência, faz uma lúcida articulação entre os desdobramentos das crises geradas pela Covid-19 com as deficiências do nosso sistema escolar, marcado "por desigualdades, exclusões, elitismo, facilitação e superficialidade", o que gera "amplos contingentes de estultos e refratários às orientações científicas de prevenção à pandemia e seu controle". Argumenta, ainda, que essa situação se agrava pelo negacionismo, fundamentalismo político e religioso, anticientificismo e conspiracionismo, que orientam as ações políticas. Retoma alguns princípios norteadores da educação científica na construção de mentalidades abertas.

Três artigos focalizam especificamente as repercussões da pandemia para a educação escolar, no que tange à situação do ensino remoto. Uma interessante análise se encontra no artigo Um sentido para a experiência escolar em tempos de pandemia, de José Sérgio Fonseca de Carvalho, pesquisador de filosofia da educação, que situa a educação escolar no contexto de crise (Arendt), como perda das referências para nossas ações. A partir desse pressuposto, o autor pondera sobre "novas oportunidades para o pensamento e a ação" que a crise proporciona e propõe a narrativa, na tradição de Ricouer, como uma forma articuladora de sentido ao esvaziamento da dimensão temporal da educação. A 
narrativa da experiência escolar, no ensino remoto, de uma adolescente aponta para a necessidade de promover junto aos alunos "a oportunidade de habitarem um outro mundo no tempo e no espaço por meio do acesso e da ressignificação de obras ficcionais e historiográficas nas quais a experiência de viver uma pandemia seja reconfigurada à luz do presente".

Em Comunicação Educativa: perspectivas e desafios com a Covid-19, Joaquim José Jacinto Escola, pesquisador português na área de filosofia e educação, retoma a perspectiva conceitual da comunicação educativa, oferendo uma análise das vinculações entre educação e comunicação (Freire, Jaspers, Marcel). Retoma a história da comunicação (Cloutier, 2001), bem como a periodização das tecnologias na educação (Costa, 2007), para indicar a "estreita relação entre os tipos de comunicação, os dispositivos utilizados, e as respostas disponibilizadas pela comunicação educativa em face dos desafios que a Covid-19". Conclui que, diante dos desafios da pandemia, o trabalho realizado por meio de plataformas de ensino a distância, no contexto português, reforçou o papel decisivo dos professores e da cooperação entre eles para articular a comunicação presencial e a comunicação a distância.

Simone Bicca Charczuk, pesquisadora da área de psicologia da educação, aborda a importante questão da transferência no ensino remoto, no artigo Sustentar a transferência no ensino remoto: docência em tempos de pandemia. Inicia com uma distinção entre ensino remoto e educação a distância (EaD), para esclarecer que os alegados problemas de interação não são inerentes a essas modalidades de ensino. Argumenta que avaliações e críticas sobre modos de ensino dependem de suas bases teóricas. Apoiada na psicanálise freudo-lacaniana, interpreta 0 processo de ensinar e de aprender a partir do conceito de transferência, reafirmando a possibilidade de estabelecer-se o laço transferencial entre professor, aluno e conhecimento no ensino remoto, "considerando a escuta e a palavra como representantes da presença e da corporeidade neste contexto".

Como qualquer texto só se efetiva com a participação do leitor, convidamos à leitura dos artigos desta Seção Temática, que representam um esforço em compreender este tempo tão desafiador, correndo o risco inerente a uma reflexão que ainda se encontra muito próxima dos acontecimentos.

Recebido em 29 de novembro de 2020 Aprovado em 18 de dezembro de 2020

\section{Notas}

1 Conforme dados fornecidos pelo infográfico da história das pandemias, no site Visual Capitalsit. Disponível em: <https://www.visualcapitalist.com/historyof-pandemics-deadliest/>. Acesso em: 05 maio 2020.

2 O poema é um elogio ao filósofo grego Epicuro (341 a. C.-270 a. C.), como se lê nestes versos: "Ó tu que primeiro pudeste, de tão grandes trevas, fazer sair um tão claro esplendor, esclarecendo-nos sobre os bens da vida, a ti eu sigo, ó 
glória do povo grego, e ponho agora meus pés sobre os sinais deixados pelos teus, não por qualquer desejo de rivalizar contigo, mas porque por amor me lanço a imitar-te" (Lucrécio, 1973, III, 1, p. 71).

3 Pinzani (2020) observa que, especialmente em relação aos governos sul-americanos, faltou uma estratégia global de combate à pandemia: "Isso se explica, por um lado, pela rapidez com a qual a epidemia se tornou pandemia, pegando de surpresa os governos, e, por outro, pela pouca ou nenhuma inclinação desses mesmos governos em confiar à OMS a gestão da crise" (Pinzani, 2020, p. 22).

4 Há uma proximidade entre a atitude ética solidária e o entendimento de especialistas na área epidemiologia no combate à pandemia, como se observa na declaração de Lipkin (2020): “A Covid-19 requer soluções globais e é encorajador ver o G20 se comprometer com um programa de vacinação mundial, em vez de buscar soluções nacionais. [...] A covid-19 nos mostrou nossa vulnerabilidade a vírus emergentes, mas também demonstrou nossa capacidade de responder com ciência, compaixão e um objetivo comum".

\section{Referências}

BOCCACCIO. Decamerão. São Paulo: Nova Cultural, 2002.

GADAMER, Hans-Georg. Hermeneutik I Wahrheit und Methode: Grundzüge einer philosophischen Hermeneutik. Gesammelte Werke. Tübingen: Mohr Siebeck, 1990. v. 1.

HABERMAS, Jürgen. Erläuterungen zur Diskursethik. Frankfurt am Main: Suhrkamp, 1991.

HABERMAS, Jürgen. Habermas über Corona: 'So viel Wissen über unser Nichtwissen gab es noch nie'. Entrevista concedida a Markus Schwering. Frankfurter Runschau, Frankfurt am Main, 10 abr. 2020. Disponível em: <https:// www.fr.de/kultur/gesellschaft/juergen-habermas-coronavirus-krise-covid19interview-13642491.html $\geq$. Acesso em: 05 maio 2020.

HÖLDERLIN, Friedrich. Patmos. Sämtliche Werke, Briefe und Dokumente. Herausgegeben Von D. E. Satller. München: Luchtverhand Literaturverlag, 2004. v. 10 .

LIPKIN, Ian. Este vírus vai continuar entre nós para sempre. Entrevista concedida a Nuño Dominguez. El País, 27 nov. 2020. Disponível em: <https://brasil.elpais.com/internacional/2020-11-26/este-virus-vai-continuar-entre-nos-parasempre.html>. Acesso em: 29 nov. 2020.

LUCRÉCIO CARO, Tito. Da Natureza. Tradução de Agostinho da Silva. São Paulo: Abril S.A., 1973.

MASSAD, Eduardo. Coronavírus pode ser só 'ensaio' de uma próxima grande epidemia. UOL, São Paulo, 05 maio 2020. Disponível em: <https://noticias.uol. com.br/saude/ultimas-noticias/bbc/2020/05/05/coronavirus-pode-ser-so-ensaio-de-proxima-grande-pandemia-diz-medico-e-matematico-da-usp.htm>. Acesso em: 10 nov. 2020.

MEAD, George Herbert. The philosophy of education. Boulder, CO: Paradigm Publishers, 2008.

NIETZSCHE, Friedrich. Ecce homo. KSA. Berlin/New York: Deutscher Taschenbuch Verlag, de Gruyter, 1988. v. 6. 
PINZANI, Alessandro. Fraqueza do Estado e elitização da cidadania na América do Sul: Lições políticas da pandemia. In: REICH, Evânia; BORGES, Maria de Lourdes; XAVIER, Raquel Cipriani (Org.). Reflexões sobre a pandemia. Florianópolis: Nefiponline, 2020. P. 21-29.

Nadja Hermann é professora titular de Filosofia da Educação aposentada da Universidade Federal do Rio Grande do Sul, Brasil.

ORCID: http://orcid.org/0000-0003-3823-7057

E-mail: nadjamhermann@gmail.com

Editora-responsável: Carla Vasques

Este é um artigo de acesso aberto distribuído sob os termos de uma Licença Creative Commons Atribuição 4.0 Internacional. Disponível em: <http:// creativecommons.org/licenses/by/4.0>. 